\title{
ABT-199 (venetoclax) and BCL-2 inhibitors in clinical development
}

\author{
Shundong Cang ${ }^{1 \dagger}$, Chaitanya Iragavarapu ${ }^{2+}$, John Savooji ${ }^{2}$, Yongping Song ${ }^{3}$ and Delong $\mathrm{Liu}^{3^{*}}$
}

\begin{abstract}
With the advent of new agents targeting CD20, Bruton's tyrosine kinase, and phosphoinositol-3 kinase for chronic lymphoid leukemia (CLL), more treatment options exist than ever before. B-cell lymphoma-2 (BCL-2) plays a major role in cellular apoptosis and is a druggable target. Small molecule inhibitors of BCL-2 are in active clinical studies. ABT-199 (venetoclax, RG7601, GDC-0199) has been granted breakthrough designation by FDA for relapsed or refractory CLL with 17p deletion. In this review, we summarized the latest clinical development of ABT-199/ venetoclax and other novel agents targeting the BCL-2 proteins.
\end{abstract}

\section{Introduction}

Tyrosine kinase inhibitors have ushered cancer treatment to the era of targeted therapy [1-7]. Monoclonal antibodies have revolutionized therapy for lymphoma [8-13]. Cancer immunotherapy highlights the latest development in clinical oncology [14-20]. In addition, novel agents/vehicles, such as Bruton's tyrosine kinase (BTK) inhibitors (e.g., ibrutinib) [21-24], chimeric T-cell receptors (e.g., CART19) [25-29], NK cell-specific antibodies (e.g., AFM13) [11, 30, 31], and CD19 BiTE antibodies $[32,33]$, are in active clinical trials. It has been well documented that B-cell lymphoma-2 (BCL-2) plays a major role in cellular apoptosis and is a druggable target. Several small molecule inhibitors of BCL-2 are in active clinical studies. ABT-199 (venetoclax, RG7601, GDC-0199) has been granted breakthrough designation by FDA for relapsed or refractory chronic lymphoid leukemia (CLL) with $17 p$ deletion. This review focused on the current clinical development of a highly effective class of small molecule BCL-2 inhibitors, including ABT-199/venetoclax.

\section{$B C L-2$ gene and $B C L-2$ proteins}

The BCL-2 gene was identified by cloning the breakpoint of a $t(14 ; 18)$ translocation which was found frequently in human B-cell lymphomas [34]. The BCL-2 gene resides on chromosome 18q21.33. The BCL-2

\footnotetext{
* Correspondence: delong_liu@nymc.edu

${ }^{\dagger}$ Equal contributors

${ }^{3}$ Henan Cancer Hospital and the Affiliated Cancer Hospital of Zhengzhou University, Zhengzhou, China

Full list of author information is available at the end of the article
}

protein has 239 amino acids and a molecular weight of $26 \mathrm{KDa}$. It was the first identified major apoptotic regulator. The ability to abrogate the death signal is a key hallmark of cancer. BCL-2 plays a major role in tumorigenesis and chemoresistance.

There are multiple proteins in the BCL-2 family [35] (Fig. 1). The pro-death proteins include BCL-2associated $\mathrm{X}$ protein (BAX), BCL-2 antagonist/killer 1 (BAK), BCL-2-associated agonist of cell death (BAD), BCL-2-like 11 (BIM), NOXA, and BCL-2 binding component 3 (PUMA), whereas the pro-survival proteins include BCL-2, BCL- $\mathrm{X}_{\mathrm{L}}, \mathrm{BCL}-2$-like 2 (BCL-w), myeloid cell leukemia sequence 1 (MCL-1), and BCL-2related protein A1 (BFL-1).

The roles of BCL-2 family proteins in cellular apoptosis and oncogenesis have been extensively studied [35, 36]. Different members of the BCL-2 family of proteins have pro- and anti-apoptotic functions, with their core function being the regulation of mitochondrial outer membrane permeability [37]. This in turn regulates the release of pro-apoptotic factors such as the second mitochondrial activator of caspases/direct inhibitor of apoptosis protein binding protein with a low isoelectric point (Smac/DIA$\mathrm{BLO}), \mathrm{Omi} / \mathrm{HtrA} 2$ [38], apoptosis-inducing factor (AIF), endonuclease G [39], and cytochrome-C [40, 41].

BCL-2 proteins can be classified into three subsets according to the number of BCL-2 homology (BH) domains [42] (Fig. 1). The presence of all four BH domains is the hallmark of all anti-apoptotic BCL-2 proteins, such as BCL-2, BCL- $\mathrm{X}_{\mathrm{L}}$, and MCL-1, as mentioned above. Pro-apoptotic BCL-2 family proteins typically 


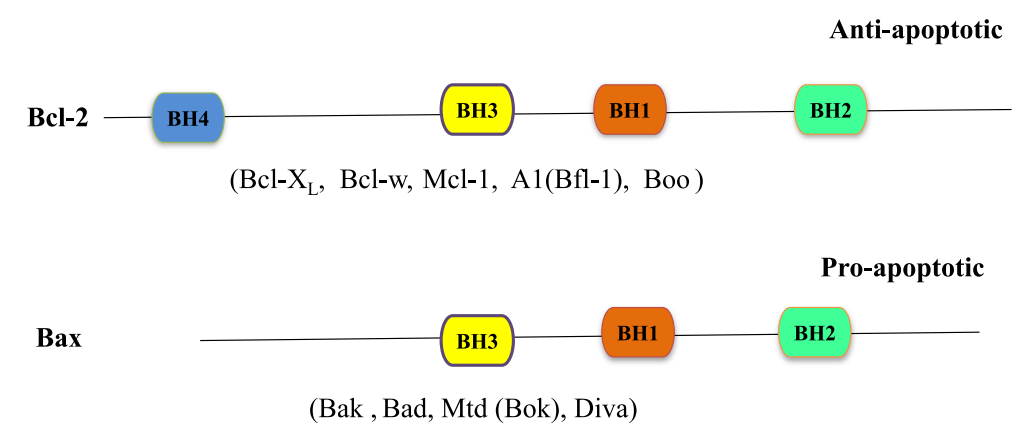

Pro-apoptotic

Bik

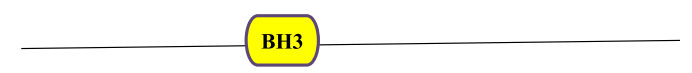

(Bid, Bim, Hrk (DPS), Blk, Bnip3, Bnip3L )

Fig. 1 Structures of BCL-2 family proteins. According to the BH domains, the BCL-2 family proteins can be categorized into three subsets. BH4-containing $B C L-2$ and related $B C L-X_{L}, B C L-W, M C L-1, A 1(B F L-1)$, and Boo are anti-apoptotic proteins. The remaining two subsets (BAX and Bik subgroups) do not have a $\mathrm{BH} 4$ domain and are pro-apoptotic proteins

have three $\mathrm{BH}$ domains and are further subdivided into the BAX subset (example: BAX and BAK) and the BH3 subset [example: $\mathrm{BH} 3$ interacting domain death agonist (Bid) and BAD] which only share homology at the BH3 domain $[43,44]$.

BCL-2 directly inhibits the influx of adenine nucleotides through the outer mitochondrial membrane. This reduces ATP hydrolysis and inhibits cytochrome- $\mathrm{C}$ release. BAX and BAK act through opposite mechanism and are pro-apoptotic. Other members of the proapoptotic pathway also function through the direct release of cytochrome-C or inhibition of BCL-2. Of note, BCL-2 also maintains cells in the $G_{0}$ phase in the absence of survival/growth factors-a potent oncogenic mechanism.

\section{BCL-2 inhibitors}

By taking the advantage of the function of BH3 subset pro-apoptotic proteins in promoting programed cell death, multiple BH3 mimetics have been developed as cancer therapeutics. They interact in an inhibitory manner with the anti-apoptotic proteins $B C L-2, B C L-X_{L}$, and BCL-w.

\section{ABT-737}

ABT-737 is a small molecule inhibitor of BCL-2, BCL$\mathrm{X}_{\mathrm{L}}$, and BCL-w [45]. ABT-737 showed in vitro activity against lymphoma and small cell carcinoma cells. Subsequent in vitro studies showed activity against myeloma $[46,47]$, acute leukemia $[48,49]$, and lymphoma. Further studies confirmed in vivo activity of ABT-737 in mouse xenograft models [50-53]. However, this compound has low solubility and oral bioavailability.

\section{ABT-263 (navitoclax)}

ABT-263 (navitoclax) is another potent small molecule inhibitor of BCL-2, BCL- $\mathrm{X}_{\mathrm{L}}$, and BCL-w. It was tested on multiple cell lines in vitro and in xenograft models [54] and shown to have significant activity against acute lymphoblastic leukemia (ALL) cell lines. Subsequent studies showed in vitro activity against leukemia and lymphoma cells [55] with efficacy replicated in mouse models for pediatric ALL [56], non-Hodgkin's lymphoma [57], and myeloma [58].

Subsequently, phase I trials of ABT-263 were carried out in lymphoid malignancies. The first trial to evaluate ABT-263/navitoclax studied two different dosing schedules in 55 patients with relapsed/refractory $(R / R)$ lymphoid malignancies [59]. The first dosing evaluation consisted of navitoclax given orally once a day at dose ranges from 10 to $440 \mathrm{mg}$ from days 1 to 14 in a 21-day cycle (intermittent schedule). The second dosing schedule consisted of navitoclax once daily at dose ranges from 200 to $425 \mathrm{mg}$ for days $1-21$ in a 21 -day cycle (continuous schedule). Due to significant thrombocytopenia reported from earlier trials, a loading dose of $150 \mathrm{mg}$ daily for $7-$ 14 days was used for the continuous dosing. The maximal tolerated dose was noted to be $315 \mathrm{mg}$ for the intermittent schedule and $325 \mathrm{mg}$ for the continuous schedule. In the intermittent schedule regimen, at $440 \mathrm{mg}$, grade III transaminitis and grade IV thrombocytopenia were observed. In the continuous-schedule regimen, grade III transaminitis and gastrointestinal bleed were observed [59]. A phase IIa study is currently ongoing.

Another phase I trial evaluated intermittent and continuous dosing in 29 patients with relapsed/refractory CLL [60]. The patients received oral navitoclax daily 
either for 14 days $(10,110,200$, or $250 \mathrm{mg} /$ day; $n=15)$ or 21 days $(125,200,250$, or $300 \mathrm{mg} /$ day; $n=14)$ of each 21-day cycle. Dose escalation was done according to a continual reassessment methodology. The phase 2 dosing was determined to be $250 \mathrm{mg}$ daily in a continuous dosing schedule. The dose-limiting toxicity (DLT) was mainly due to dose-related thrombocytopenia. Efficacy data showed partial response in 9 (31\%) of the patients and stable disease in 18 patients ( 8 with durable SD > 6 months, $7>12$ months). Reduction in lymphocytosis was seen in $50 \%$ of the evaluable patients. Median progression-free survival was 25 months. Navitoclax was found to have activity in high-risk patients with fludarabine-refractory disease, bulky adenopathy, and $\operatorname{del}(17 p)$ CLL.

\section{ABT-199 (venetoclax, RG7601, GDC-0199) Preclinical studies of ABT-199}

The dose-limiting severe thrombocytopenia from ABT263/navitoclax quenched the enthusiasm for further clinical development of this compound. Preclinical studies of ABT-737 also revealed decreased platelet survival [61]. A seminal study by Mason et al. [62] had previously highlighted the importance of $\mathrm{BCL}-\mathrm{X}_{\mathrm{L}}$ in platelet survival, its role in the pro-apoptotic activity of BAK, and a gradual reduction in $\mathrm{BCL}-\mathrm{X}_{\mathrm{L}}$ levels culminating in the apoptosis of senescent platelets. The term molecular clock was used to describe this temporal switch from anti-apoptosis to pro-apoptosis [62]. Therefore, BCL- $\mathrm{X}_{\mathrm{L}}$ inhibition could speed up this molecular clock and lead to decreased platelet survival-the mechanism implicated in ABT-737/ABT-263-induced thrombocytopenia.

The need to develop a BCL-2 inhibitor sparing BCL$\mathrm{X}_{\mathrm{L}}$ and platelets sparked the discovery and development of ABT-199 (venetoclax) [63]. X-ray complex-based structures determined the presence of high-affinity interactions in two hydrophobic pockets in the threedimensional structure of anti-apoptotic BCL-2 proteins. These hot spots, named P2 and P4, bind to the 1chloro-4-(4,4-dimethylcyclohex-1-enyl)benzene and the thiophenyl moiety of navitoclax, respectively. Along with the hydrophobic interactions, electrostatic interactions between arginine residues (on anti-apoptotic proteins) and aspartate residues (on pro-apoptotic molecules) were also underscored. Through reverse engineering of navitoclax, structural modifications were made so that a new molecule was created to have similar hydrophobic interaction but different electrostatic interaction with Arg103 (specific to BCL-2 since BCL- $\mathrm{X}_{\mathrm{L}}$ has Glu96). This led to the discovery of BCL-2 binding molecule, ABT-199.

ABT-199 (venetoclax) represents the first-in-class, selective, oral BCL-2 inhibitor sparing platelets [63]. It showed sub-nanomolar affinity to BCL-2 $\left(K_{\mathrm{i}}<0.010 \mathrm{nM}\right)$ with antitumor activity against non-Hodgkin's lymphoma (NHL) [63], CLL [64], and acute leukemias [65, 66] in vitro. In vivo mouse xenograft studies showed activity against aggressive (Myc+) lymphomas [67] as well as acute leukemia [68].

BCL-2 over-expression plays a central role in follicular lymphoma (FL). In vitro studies were done to characterize the effects of ABT-199 in the t(14;18)+ FL cell lines WSUFSCCL and FC-TxFL2 and in primary FL cells [69]. JNK kinase phosphorylation and inactivation as well as substantial decrease of mitochondrial potential in FC-TxFL2 cells were induced by ABT-199. Similar expression levels were seen in the anti-apoptotic (such as BCL-2, BCL- $\mathrm{X}_{\mathrm{L}}$, MCL-1) and pro-apoptotic proteins (such as BAX, PUMA, BAK, BAD, NOXA, Bid, Bok) in both cell lines. No significant change was seen in these proteins upon ABT-199 treatment. In this study, the ABT-199 resistant cell line was established. Increased levels of MCL-1 and elevated phosphorylation of BCL-2 on T56 and of AKT on S473 were demonstrated. In addition, increased autophagy was shown in comparison to parental cells. It was also demonstrated in this study that the combination of two epigenetic agents, decitabine and vorinostat, was able to overcome ABT-199 resistance. Even though ABT-199 should be theoretically active in FL as a BH3 mimetic, activity in patients with FL has not been as dramatic as has been observed for CLL. Acquired resistance developed easily in the in vivo study in the xenograft model, which may explain the relatively higher failure possibility in $\mathrm{FL}$ than in CLL.

ABT-199 was studied in combinations with tyrosine kinase inhibitors (TKIs), including imatinib, nilotinib, dasatinib, or ponatinib, in cells from six patients with blast-crisis chronic myeloid leukemia (CML) [70]. All six patients were resistant to TKIs, three of them with T315I mutation. This study further revealed in a CML mouse model that ABT-199 alone or in combination was better than nilotinib in eradicating CML stem cells in vivo.

A combination of ibrutinib and ABT-199 was also studied in mantle cell lymphoma (MCL) and CLL [71]. The ibrutinib and ABT-199 combination substantially induced apoptosis of primary cells from MCL and CLL patients compared to each single agent alone (combo: 23 \%, ibrutinib: 3.8 \%, ABT-199: $3.0 \%$ ). When BCL-2 and BTK target genes as well as emergent genes were characterized using a protein-protein network interaction model, synergistic activation of apoptosis genes of p53 and BIM was revealed. Little off-target effect was seen with the combination nor with individual drugs on normal peripheral $\mathrm{T}$ cells [71].

Selinexor (KPT-330), a first-in-class selective inhibitor of nuclear export (SINE) agent, has been shown to have antiproliferative and pro-apoptotic activities against 
MCL and other cancer cells [72-76]. A combination of ABT-199 and selinexor was studied in MCL cell lines [77]. The combination demonstrated synergistic antiproliferative effects through inhibition of mTOR signaling, downregulation of ribosomal biosynthesis, and induction of mitochondria-mediated apoptosis.

MCL-1, an anti-apoptotic protein, is one of the main targets of homoharringtonine (HHT) and omacetaxine, both of which have been in clinical applications [78, 79]. To test the dual inhibition of BCL-2 and MCL-1, HHT and ABT-199 were combined and tested in seven diffuse large B-cell lymphoma cell lines [80]. The study confirmed decreased expression of MCL-1 protein in all the cell lines. It was also demonstrated that high expression of BCL-2 positively correlated with sensitivity to ABT199 , irrespective of expression levels of $B C L-X_{L}$ and MCL-1. BCL-2 and BCL- $\mathrm{X}_{\mathrm{L}}$ expression levels negatively correlated with sensitivity to HHT. However, the expression level of MCL-1 did not correlate with sensitivity to HHT.

\section{Clinical studies of ABT-199}

Preliminary data from a phase I trial of ABT-199 showed an overall response rate (ORR) of $84 \%$ in 56 patients with relapsed/refractory CLL [81] (Table 1). At a median follow-up of 10.9 months, a complete response (CR) of $23 \%$ and partial response (PR) of $61 \%$ were achieved. ABT-199 dosages of 150-1200 mg given once on days 3 or 7 followed by once daily were used. Diarrhea (46\%), neutropenia (43\%), fatigue (34\%), upper respiratory tract infection (29\%), and cough (25\%) were the most common side effects. Dose-limiting toxicities (DLTs) were reported to include six tumor lysis syndromes (TLSs), one sudden death, and one grade IV neutropenia. TLS complication is now better prevented with a lead-in dose-escalation step [82].

The latest update showed an ORR of $79 \%$ in 84 patients with relapsed/refractory (R/R) CLL with median duration of response of 20.5 months. The most common adverse events (AEs) remained similar-neutropenia (39\%), diarrhea (36\%), nausea (35\%), upper respiratory tract infection (31 \%), and fatigue (27\%). Grade $3 / 4$ AEs

Table 1 Single agent clinical trials of venetoclax/ABT-199

\begin{tabular}{llll}
\hline Clinical trials & Diseases & Responses & References \\
\hline Phase I & R/R CLL & ORR-79\% & 81,83 \\
Phase la & R/R NHL & ORR-48\% & 84 \\
Phase II & R/R AML & ORR-15\% & 85 \\
& New AML & & \\
\hline
\end{tabular}

$R / R$ relapsed/refractory, ORR overall response rate, $C L L$ chronic lymphoid leukemia, NHL non-Hodgkin's lymphoma, AML acute myeloid leukemia included neutropenia, anemia, TLS (8\% including one death), and thrombocytopenia (7\%) [83].

A phase Ia trial of ABT-199 in R/R NHL used continuous daily dosing of $200-900 \mathrm{mg}$. A single dose was administered on day 7 followed by a lead-in period with stepwise upward titration over $2-3$ weeks. An ORR of $48 \%$ was achieved in 40 patients with responses across various NHL subtypes; the most common AEs included nausea (34\%), upper respiratory tract infection (27\%), diarrhea (25\%), and fatigue (21\%). DLTs included subclinical TLS (based on laboratory criteria) [84].

The single-agent ABT-199 was studied in a phase 2, open-label, multicenter trial in patients (pts) with highrisk R/R AML and in untreated patients who were unfit for intensive chemotherapy [85]. The study allowed intra-patient dose escalation when a patient received $20 \mathrm{mg}$ ABT-199 on week (Wk) 1 day 1 . Daily escalation was implemented to target a final dose of $800 \mathrm{mg}$ on day 6 and daily thereafter. Those patients without a CR or $\mathrm{CR}$ with incomplete hematological recovery $(\mathrm{CRi})$ at the first scheduled assessment (end of Wk 4) were able to escalate to $1200 \mathrm{mg}$. Of the 32 pts enrolled, 30 (93.8 \%) had R/R disease, 12 (37.5\%) had a history of myelodysplastic syndrome, and $2(6 \%)$ had a history of myeloproliferative neoplasms. The patients were heavily pretreated. Fourteen $(44 \%)$ had progressed through at least three prior treatments and $22(69 \%)$ had failed hypomethylating agents. The most common treatment emergent AEs (TEAEs) (in $\geq 25 \%$ of patients) were nausea, diarrhea, fatigue, neutropenia, and vomiting. Severe AEs were febrile neutropenia, anemia, and pneumonia. One CR and four CRi were seen at first assessment. Of the five patients with CR/CRi, three had IDH mutation. The ORR was $15.5 \%$ (5/32). Therefore, ABT-199 appears to have considerable single-agent clinical activity in patients with poor prognosis R/R AML. It is worthy of note that patients with IDH mutation may be particularly sensitive to ABT-199.

\section{ABT-199 in combination regimens}

A phase Ib trial of ABT-199 in combination with rituximab (R) in patients with relapsed/refractory CLL enrolled 37 patients. Rituximab dosage was $375 \mathrm{mg} / \mathrm{m}^{2}$ titrated to $500 \mathrm{mg} / \mathrm{m}^{2}$ monthly for 6 months. ABT-199 dosages began at $20 \mathrm{mg}$ titrated weekly to $200-600 \mathrm{mg}$. Eighteen patients had completed therapy with $39 \%$ showing CR and $39 \%$ achieving PR (ORR $78 \%$ ). Most common AEs included neutropenia (43\%), nausea (38\%), and diarrhea (30\%). DLTs were reported to be thrombocytopenia and hemophagocytic syndrome [86]. An update of the study was reported at $2014 \mathrm{ASH}$ which included 49 pts in five dose-escalation cohorts $(n=41)$ and one safety expansion cohort $(n=8)$ [87]. The patients were heavily pretreated, with a median number of prior therapies at 3 (range 1-10). Thirteen patients 
(27\%) were refractory to fludarabine and nine (18\%) were R-refractory. Among them also included nine (18\%) with $\operatorname{del}(17 \mathrm{p})$. The ORR was $88 \%$, with 11 (32\%) achieving a CR/CRi and 20 (56 \%) achieving PR in the 34 pts who were evaluable for response in doseescalation cohorts. The recommended phase 2 dose (RPTD) of ABT-199 is $400 \mathrm{mg}$ daily. The combination of ABT-199 and R was well tolerated and induced an ORR of $86 \%$ with $31 \%$ CRs in pts with CLL/SLL [87]. A phase 3 trial comparing ABT-199 and R versus bendamustine and $\mathrm{R}$ in pts with previously treated CLL is underway (NCT02005471) [88] (Table 2).

A phase I, open-label, multicenter study of ABT-199 in combination with bendamustine (B) and rituximab (R) was reported in patients with R/R NHL [89]. In the dose-escalation portion of the study, ABT-199 doses ranged from 50 to $400 \mathrm{mg}$. Dosing schedules were as follows: 3,7 , and 28 days/cycle in each 28 -day cycle. Standard $\mathrm{BR}$ treatment for six cycles were given as the following: B (2 days/cycle, $\left.90 \mathrm{mg} / \mathrm{m}^{2}\right)$ and R (1 day/cycle, $375 \mathrm{mg} / \mathrm{m}^{2}$ ). ABT-199 followed by BR was administered on day 1 of cycles 4-6. Upon completion of BR treatment, ABT-199 was continued as monotherapy. At the last update in July 2014, 26 patients have received ABT199 in combination with BR. Fifteen (57.7 \%) patients had follicular lymphoma (FL), eight (30.8 \%) had diffuse large B-cell lymphoma (DLBCL), and three (11.5\%) had marginal zone lymphoma (MZL). Out of 26 patients, 11 (42\%) had completed six cycles of BR treatment. The most common TEAEs included nausea (65.4 \%), anemia and neutropenia (each in $42.3 \%$ ), diarrhea (38.5 \%), and thrombocytopenia (34.6\%). Severe AEs included neutropenia $(26.9 \%)$ and anemia and thrombocytopenia (each in $19.2 \%$ ). DLTs included febrile neutropenia and thrombocytopenia. Dosing schedule was modified to 7 days/cycle for patients in cohort 6. G-CSF prophylaxis was added. No DLTs were observed in the subsequent

Table 2 Clinical trials of venetoclax/ABT-199 in combination regimens

\begin{tabular}{lllll}
\hline Clinical trials & Regimens & Diseases & Responses & References \\
\hline Phase Ib & $V+R$ & R/R CLL & ORR-88 \% & 86,87 \\
& & & CR/CRi-32\% & \\
& & & PR-56\% & \\
Phase I & $V+B R$ & R/R NHL & ORR-61.5\% & 89 \\
Phase Ib & $V+B R$ & R/R CLL & Not reported & 90 \\
& & Untreated CLL & \\
Phase Ib & $V+O$ & R/R CLL & Not reported & 91 \\
& & Untreated CLL & \\
\hline
\end{tabular}

$R / R$ relapsed/refractory, ORR overall response rate, $C L L$ chronic lymphoid leukemia, $N H L$ non-Hodgkin's lymphoma, $A M L$ acute myeloid leukemia. For regimens: $V$ venetoclax, $R$ rituximab, $B$ bendamustine, $O$ obinutuzumab cohorts. The overall response rate $(\mathrm{CR}+\mathrm{PR})$ for $\mathrm{ABT}-$ $199+$ BR was $61.5 \%(16 / 26)$ for all patients, $73.3 \%(11 /$ 15) for patients with FL, and $37.5 \%$ (3/8) for patients with DLBCL. Further enrollment employed $400 \mathrm{mg}$ ABT-199 with re-examination of a 28-day cycle schedule with G-CSF prophylaxis in heavily pretreated patients. A phase 2 study (NCT02187861; BO29337) of ABT-199 + $\mathrm{BR}$ in R/R FL was planned.

Another phase 1b study evaluated the MTD of ABT-199 in combination with $B R$ in $R / R$ or previously untreated patients (pts) with CLL [90]. Dosages ranged from 100 to $600 \mathrm{mg} /$ day of ABT-199 using a $3+3$ dose-escalation design. The study also incorporated a gradual dose ramp-up of ABT-199 to reduce the risk of TLS. A preliminary report summarized the data on six pts with $R / R$ CLL, including three pts in the 100-mg cohort and three pts in the 200-mg cohort. TLS risks were considered for risk stratification. The most common $\mathrm{AE}$ was anemia with most grade 3 AEs being hematological toxicities. There was no TLS as a result of the ramp-up dosing of ABT-199 and prophylactic measures. Dose escalation in $R / R$ pts was ongoing. Enrollment of previously untreated pts was also planned.

In another phase Ib study, ABT-199 was combined with obinutuzumab in $R / R$ or previously untreated patients with CLL [91]. ABT-199 dosage ranged from 100 to $600 \mathrm{mg} /$ day. A gradual dose ramp-up of ABT-199 and staggering of the two agents were applied to reduce the risk of tumor lysis syndrome (TLS). After completing combination therapy, ABT-199 was continued until disease progression. Nine patients were enrolled in the preliminary report, including three in the 100-mg ABT-199 dosing cohort and six in the 200-mg dosing cohort. Laboratory TLS (characterized by asymptomatic laboratory abnormalities in potassium and phosphate) was observed in 1 of the first 3 patients. One patient had a dose reduction from 100 to $50 \mathrm{mg}$ per day due to prolonged neutropenia but subsequently completed six cycles of combination treatment. For obinutuzumab, infusionrelated reactions were seen but limited to the first infusion. The combination was safe and well tolerated. No clinical TLS was observed in these nine patients. Dose escalation of ABT-199 was done in those R/R patients at $400 \mathrm{mg} /$ day.

The phase II trial of ABT-199 in 17p (-) relapsed/refractory CLL patients (NCT01889186 [92]) is underway. Apart from this, multiple studies evaluating ABT-199 in multiple myeloma (NCT01794507, NCT01794520), CLL (NCT02242942, NCT01685892, NCT01671904, NCT02427451, NCT02141282, NCT02401503), and NHL (NCT02187861, NCT02558816, NCT02055820, NCT02471391, NCT02419560, NCT01594229) are currently active. 


\section{Conclusion and future directions}

ABT-199/venetoclax showed high response rate as a single agent in refractory/relapsed CLL. In particular, high CR rate was reported in refractory/relapsed CLL (29\% as single agent, $39 \%$ in combination with rituximab). This is quite different from ibrutinib, which acts slowly and rarely induces $\mathrm{CR}$ as a single agent in this population of patients. Resistance in lymphoid cells to ABT199 has been reported [93]. Combination regimens to counteract these mechanisms are being evaluated [94, 95]. The lack of BCL- $X_{L}$ inhibition with ABT-199 significantly reduced the dose-limiting thrombocytopenia. Since BCL-2 plays a major role as an anti-apoptotic protein in multiple hematological malignancies, ABT-199 has the potential to be effective as a single agent or in combination with other agents toward a broad spectrum of hematological malignancies. ABT-199 therefore may lead to the shift of current treatment paradigms in hematological cancers.

\section{Competing interest}

The authors have no relevant conflicts of interest.

\section{Authors' contributions}

$\mathrm{DL}, \mathrm{Cl}$, and SC designed the study and drafted the manuscript. SC and $\mathrm{Cl}$ contributed equally to the study. JS and YS have provided comments and contributed to revising the manuscript. All authors have read and approved the final manuscript.

\section{Acknowledgements}

This study was partly supported by the Henan Cancer Hospital and the Affiliated Cancer Hospital of Zhengzhou University, Zhengzhou, China.

\author{
Author details \\ 'Department of Oncology, The Henan Province People's Hospital, \\ Zhengzhou, China. ${ }^{2}$ Department of Medicine, Westchester Medical Center \\ and New York Medical College, Valhalla, New York 10595, USA. ${ }^{3}$ Henan \\ Cancer Hospital and the Affiliated Cancer Hospital of Zhengzhou University, \\ Zhengzhou, China
}

Received: 28 October 2015 Accepted: 10 November 2015 Published online: 20 November 2015

\section{References}

1. Akinleye A, Avvaru P, Furqan M, Song Y, Liu D. Phosphatidylinositol 3-kinase (PI3K) inhibitors as cancer therapeutics. J Hematol Oncol. 2013;6(1):88.

2. Akinleye A, Furqan M, Mukhi N, Ravella P, Liu D. MEK and the inhibitors: from bench to bedside. J Hematol Oncol. 2013;6(1):27.

3. Furqan M, Akinleye A, Mukhi N, Mittal V, Chen Y, Liu D. STAT inhibitors for cancer therapy. J Hematol Oncol. 2013;6(1):90.

4. Furqan M, Mukhi N, Lee B, Liu D. Dysregulation of JAK-STAT pathway in hematological malignancies and JAK inhibitors for clinical application. Biomark Res. 2013;1(1):5.

5. Huang T, Karsy M, Zhuge J, Zhong M, Liu D. B-Raf and the inhibitors: from bench to bedside. J Hematol Oncol. 2013;6(1):30

6. Saha M, Qiu L, Chang H. Targeting p53 by small molecules in hematological malignancies. J Hematol Oncol. 2013;6(1):23.

7. Furman RR, Sharman JP, Coutre SE, Cheson BD, Pagel JM, Hillmen $P$, et al. Idelalisib and rituximab in relapsed chronic lymphocytic leukemia. N Engl J Med. 2014;370(11):997-1007.

8. Goede V, Fischer K, Busch R, Engelke A, Eichhorst B, Wendtner CM, et al. Obinutuzumab plus chlorambucil in patients with CLL and coexisting conditions. N Engl J Med. 2014;370(12):1101-10.
9. Mellor J, Brown M, Irving H, Zalcberg J, Dobrovic A. A critical review of the role of Fc gamma receptor polymorphisms in the response to monoclonal antibodies in cancer. J Hematol Oncol. 2013;6(1):1.

10. Suresh T, Lee L, Joshi J, Barta S. New antibody approaches to lymphoma therapy. J Hematol Oncol. 2014;7(1):58.

11. Wu J, Fu J, Zhang M, Liu D. AFM13: a first-in-class tetravalent bispecific anti-CD30/CD16A antibody for NK cell-mediated immunotherapy. J Hematol Oncol. 2015;8:96

12. Younes A, Bartlett NL, Leonard JP, Kennedy DA, Lynch CM, Sievers EL, et al. Brentuximab vedotin (SGN-35) for relapsed CD30-positive lymphomas. N Engl J Med. 2010;363(19):1812-21.

13. Hillmen P, Robak T, Janssens A, Babu KG, Kloczko J, Grosicki S, et al. Chlorambucil plus ofatumumab versus chlorambucil alone in previously untreated patients with chronic lymphocytic leukaemia (COMPLEMENT 1): a randomised, multicentre, open-label phase 3 trial. Lancet. 2015;385(9980): 1873-83.

14. Ansell SM, Lesokhin AM, Borrello I, Halwani A, Scott EC, Gutierrez M, et al. PD-1 blockade with nivolumab in relapsed or refractory Hodgkin's lymphoma. N Engl J Med. 2015;372(4):311-9.

15. Garon EB, Rizvi NA, Hui R, Leighl N, Balmanoukian AS, Eder JP, et al. Pembrolizumab for the treatment of non-small-cell lung cancer. N Engl J Med. 2015;372(21):2018-28.

16. Postow MA, Callahan MK, Wolchok JD. Immune checkpoint blockade in cancer therapy. J Clin Oncol. 2015;33(17):1974-82.

17. Postow MA, Chesney J, Pavlick AC, Robert C, Grossmann K, McDermott D, et al. Nivolumab and ipilimumab versus ipilimumab in untreated melanoma. N Engl J Med. 2015;372(21):2006-17.

18. Robert C, Long GV, Brady B, Dutriaux C, Maio M, Mortier L, et al. Nivolumab in previously untreated melanoma without BRAF mutation. N Engl J Med. 2015:372(4):320-30.

19. Robert C, Schachter J, Long GV, Arance A, Grob JJ, Mortier L, et al. Pembrolizumab versus ipilimumab in advanced melanoma. N Engl J Med. 2015;372(26):2521-32.

20. Shi $L$, Chen S, Yang L, Li Y. The role of PD-1 and PD-L1 in T-cell immune suppression in patients with hematological malignancies. J Hematol Oncol. 2013;6(1):74.

21. Novero A, Ravella P, Chen Y, Dous G, Liu D. Ibrutinib for B cell malignancies. Exp Hematol Oncol. 2014;3(1):4

22. Akinleye A, Chen Y, Mukhi N, Song Y, Liu D. Ibrutinib and novel BTK inhibitors in clinical development. J Hematol Oncol. 2013;6:59.

23. Byrd JC, Brown JR, O'Brien S, Barrientos JC, Kay NE, Reddy NM, et al. Ibrutinib versus ofatumumab in previously treated chronic lymphoid leukemia. N Engl J Med. 2014;371(3):213-23.

24. Byrd JC, Furman RR, Coutre SE, Flinn IW, Burger JA, Blum KA, et al. Targeting BTK with ibrutinib in relapsed chronic lymphocytic leukemia. N Engl J Med. 2013;369(1):32-42.

25. Han E, Li X-I, Wang C-r, Li T-f, Han S-Y. Chimeric antigen receptor-engineered T cells for cancer immunotherapy: progress and challenges. J Hematol Oncol. 2013;6(1):47.

26. Haso W, Lee DW, Shah NN, Stetler-Stevenson M, Yuan CM, Pastan $I H$, et al. Anti-CD22-chimeric antigen receptors targeting B-cell precursor acute lymphoblastic leukemia. Blood. 2012;121(7):1165-74.

27. Ruella M, Barrett D, Kenderian SS, Shestova O, Hofmann TJ, Scholler J, et al. Novel chimeric antigen receptor T cells for the treatment of CD19-negative relapses occurring after CD19-targeted immunotherapies. Blood. 2014;124(21):966

28. Chen Y, Liu D. Chimeric antigen receptor (CAR)-directed adoptive immunotherapy: a new era in targeted cancer therapy. Stem Cell Investig. 2014;1:2.

29. Sadelain M, Brentjens R, Riviere I. The basic principles of chimeric antigen receptor design. Cancer Discov. 2013;3(4):388-98.

30. Reusch U, Burkhardt C, Fucek I, Le Gall F, Le Gall M, Hoffmann K, et al. A novel tetravalent bispecific TandAb (CD30/CD16A) efficiently recruits NK cells for the lysis of CD30+ tumor cells. MAbs. 2014;6(3):728-73.

31. Rothe A, Sasse S, Topp MS, Eichenauer DA, Hummel H, Reiners KS, et al. A phase 1 study of the bispecific anti-CD30/CD16A antibody construct AFM13 in patients with relapsed or refractory Hodgkin lymphoma. Blood. 2015;125(26):4024-31.

32. Breton C, Nahimana A, Aubry D, Macoin J, Moretti P, Bertschinger M, et al. A novel anti-CD19 monoclonal antibody (GBR 401) with high killing activity against B cell malignancies. J Hematol Oncol. 2014;7(1):33. 
33. Wu J, Fu J, Zhang M, Liu D. Blinatumomab: a bispecific T cell engager (BiTE) antibody against CD19/CD3 for refractory acute lymphoid leukemia. J Hematol Oncol. 2015;8:104.

34. Tsujimoto Y, Finger LR, Yunis J, Nowell PC, Croce CM. Cloning of the chromosome breakpoint of neoplastic B cells with the $t(14 ; 18)$ chromosome translocation. Science. 1984;226(4678):1097-9.

35. Tsujimoto Y, Shimizu S. Bcl-2 family: life-or-death switch. FEBS Lett. 2000; 466(1):6-10.

36. Tsujimoto $\mathrm{Y}$. Role of $\mathrm{BCl}-2$ family proteins in apoptosis: apoptosomes or mitochondria? Genes Cells. 1998;3(11):697-707.

37. McClintock DS, Santore MT, Lee WY, Brunelle J, Budinger GR, Zong WX, et al. $\mathrm{BCl}-2$ family members and functional electron transport chain regulate oxygen deprivation-induced cell death. Mol Cell Biol. 2002;22(1):94-104.

38. Yamaguchi H, Bhalla K, Wang HG. Bax plays a pivotal role in thapsigargininduced apoptosis of human colon cancer HCT116 cells by controlling Smac/Diablo and Omi/HtrA2 release from mitochondria. Cancer Res. 2003;63(7):1483-9.

39. Susin SA, Zamzami N, Castedo M, Hirsch T, Marchetti P, Macho A, et al. Bcl-2 inhibits the mitochondrial release of an apoptogenic protease. J Exp Med. 1996;184(4):1331-41.

40. Kluck RM, Bossy-Wetzel E, Green DR, Newmeyer DD. The release of cytochrome $\mathrm{C}$ from mitochondria: a primary site for $\mathrm{BCl}-2$ regulation of apoptosis. Science. 1997;275(5303):1132-6.

41. Yang J, Liu X, Bhalla K, Kim CN, Ibrado AM, Cai J, et al. Prevention of apoptosis by $\mathrm{Bcl}-2$ : release of cytochrome $\mathrm{c}$ from mitochondria blocked. Science. 1997;275(5303):1129-32.

42. Adams JM, Cory S. The BCl-2 protein family: arbiters of cell survival. Science. 1998;281(5381):1322-6

43. Kelekar A, Thompson CB. BCl-2-family proteins: the role of the $\mathrm{BH} 3$ domain in apoptosis. Trends Cell Biol. 1998;8(8):324-30.

44. Chao DT, Korsmeyer SJ. BCL-2 family: regulators of cell death. Annu Rev Immunol. 1998;16:395-419.

45. Oltersdorf T, Elmore SW, Shoemaker AR, Armstrong RC, Augeri DJ, Belli BA, et al. An inhibitor of BCl-2 family proteins induces regression of solid tumours. Nature. 2005;435(7042):677-81.

46. Chauhan D, Velankar M, Brahmandam M, Hideshima T, Podar K, Richardson $P$, et al. A novel $B C l-2 / B C l-X(L) / B C l-w$ inhibitor $A B T-737$ as therapy in multiple myeloma. Oncogene. 2007;26(16):2374-80.

47. Kline MP, Rajkumar SV, Timm MM, Kimlinger TK, Haug JL, Lust JA, et al. $\mathrm{ABT}-737$, an inhibitor of $\mathrm{BCl}-2$ family proteins, is a potent inducer of apoptosis in multiple myeloma cells. Leukemia. 2007;21(7):1549-60.

48. Konopleva M, Contractor R, Tsao T, Samudio I, Ruvolo PP, Kitada S, et al. Mechanisms of apoptosis sensitivity and resistance to the $\mathrm{BH} 3$ mimetic ABT-737 in acute myeloid leukemia. Cancer Cell. 2006;10(5):375-88.

49. Del Gaizo MV, Schlis KD, Sallan SE, Armstrong SA, Letai A. BCL-2 dependence and ABT-737 sensitivity in acute lymphoblastic leukemia. Blood. 2008;111(4):2300-9.

50. Ishitsuka K, Kunami N, Katsuya H, Nogami R, Ishikawa C, Yotsumoto F, et al. Targeting BCl-2 family proteins in adult T-cell leukemia/lymphoma: in vitro and in vivo effects of the novel BCl-2 family inhibitor ABT-737. Cancer Lett. 2012;317(2):218-25.

51. Mason KD, Vandenberg CJ, Scott CL, Wei AH, Cory S, Huang DC, et al. In vivo efficacy of the $\mathrm{BCl}-2$ antagonist $\mathrm{ABT}-737$ against aggressive Myc-driven lymphomas. Proc Natl Acad Sci U S A. 2008;105(46):17961-6.

52. High LM, Szymanska B, Wilczynska-Kalak U, Barber N, O'Brien R, Khaw SL, et al. The $\mathrm{BCl}-2$ homology domain 3 mimetic ABT-737 targets the apoptotic machinery in acute lymphoblastic leukemia resulting in synergistic in vitro and in vivo interactions with established drugs. Mol Pharmacol. 2010;77(3): 483-94.

53. Kang MH, Kang YH, Szymanska B, Wilczynska-Kalak U, Sheard MA, Harned TM, et al. Activity of vincristine, L-ASP, and dexamethasone against acute lymphoblastic leukemia is enhanced by the $\mathrm{BH} 3$-mimetic $\mathrm{ABT}$-737 in vitro and in vivo. Blood. 2007;110(6):2057-66.

54. Lock R, Carol H, Houghton PJ, Morton CL, Kolb EA, Gorlick R, et al. Initial testing (stage 1) of the $\mathrm{BH} 3$ mimetic ABT-263 by the pediatric preclinical testing program. Pediatr Blood Cancer. 2008;50(6):1181-9.

55. Ackler S, Xiao Y, Mitten MJ, Foster K, Oleksijew A, Refici M, et al. ABT-263 and rapamycin act cooperatively to kill lymphoma cells in vitro and in vivo. Mol Cancer Ther. 2008;7(10):3265-74.

56. Suryani S, Carol H, Chonghaile TN, Frismantas V, Sarmah C, High L, et al. Cell and molecular determinants of in vivo efficacy of the $\mathrm{BH} 3$ mimetic ABT-263 against pediatric acute lymphoblastic leukemia xenografts. Clin Cancer Res. 2014;20(17):4520-31.

57. Ackler S, Mitten MJ, Chen J, Clarin J, Foster K, Jin S, et al. Navitoclax (ABT-263) and bendamustine $+/$ - rituximab induce enhanced killing of non-Hodgkin's lymphoma tumours in vivo. Br J Pharmacol. 2012;167(4):881-91.

58. Ackler S, Mitten MJ, Foster K, Oleksijew A, Refici M, Tahir SK, et al. The Bcl-2 inhibitor ABT-263 enhances the response of multiple chemotherapeutic regimens in hematologic tumors in vivo. Cancer Chemother Pharmacol. 2010;66(5):869-80.

59. Wilson WH, O'Connor OA, Czuczman MS, LaCasce AS, Gerecitano JF, Leonard JP, et al. Navitoclax, a targeted high-affinity inhibitor of $\mathrm{BCL}-2$, in lymphoid malignancies: a phase 1 dose-escalation study of safety, pharmacokinetics, pharmacodynamics, and antitumour activity. Lancet Oncol. 2010;11(12):1149-59.

60. Roberts AW, Seymour JF, Brown JR, Wierda WG, Kipps TJ, Khaw SL, et al. Substantial susceptibility of chronic lymphocytic leukemia to BCL2 inhibition: results of a phase I study of navitoclax in patients with relapsed or refractory disease. J Clin Oncol. 2012;30(5):488-96.

61. Zhang H, Nimmer PM, Tahir SK, Chen J, Fryer RM, Hahn KR, et al. BCl-2 family proteins are essential for platelet survival. Cell Death Differ. 2007; 14(5):943-51.

62. Mason KD, Carpinelli MR, Fletcher Jl, Collinge JE, Hilton AA, Ellis S, et al. Programmed anuclear cell death delimits platelet life span. Cell. 2007;128(6): $1173-86$.

63. Souers AJ, Leverson JD, Boghaert ER, Ackler SL, Catron ND, Chen J, et al. ABT-199, a potent and selective BCL-2 inhibitor, achieves antitumor activity while sparing platelets. Nat Med. 2013;19(2):202-8.

64. Vogler M, Dinsdale D, Dyer MJ, Cohen GM. ABT-199 selectively inhibits BCL2 but not BCL2L1 and efficiently induces apoptosis of chronic lymphocytic leukaemic cells but not platelets. Br J Haematol. 2013;163(1):139-42.

65. Pan R, Hogdal $\amalg$, Benito JM, Bucci D, Han L, Borthakur G, et al. Selective BCL-2 inhibition by ABT-199 causes on-target cell death in acute myeloid leukemia. Cancer Discov. 2014;4(3):362-75.

66. Khaw SL, Merino D, Anderson MA, Glaser SP, Bouillet P, Roberts AW, et al. Both leukaemic and normal peripheral $B$ lymphoid cells are highly sensitive to the selective pharmacological inhibition of prosurvival $\mathrm{BCl}-2$ with ABT-199. Leukemia. 2014;28(6):1207-15.

67. Vandenberg CJ, Cory S. ABT-199, a new BCl-2-specific BH3 mimetic, has in vivo efficacy against aggressive Myc-driven mouse lymphomas without provoking thrombocytopenia. Blood. 2013;121(12):2285-8.

68. Peirs S, Matthijssens F, Goossens S, Van de Walle I, Ruggero K, de Bock CE, et al. ABT-199 mediated inhibition of BCL-2 as a novel therapeutic strategy in T-cell acute lymphoblastic leukemia. Blood. 2014;124(25):3738-47.

69. Bodo J, Zhao X, Smith MR, Hsi ED. Activity of ABT-199 and acquired resistance in follicular lymphoma cells. Blood. 2014;124(21):3635-5.

70. Carter BZ, Mak PY, Mu H, Zhou H, Mak DH, Schober WD, et al. Cooperative targeting of $\mathrm{BCl}-2$ family proteins by ABT-199 (GDC-0199) and tyrosine kinase inhibitors to eradicate blast crisis CML and CML stem/progenitor cells. Blood. 2014;124(21):512-2.

71. Portell CA, Axelrod M, Brett LK, Gordon VL, Capaldo B, Xing JC, et al. Synergistic cytotoxicity of ibrutinib and the BCL2 antagonist, ABT-199(GDC0199) in mantle cell lymphoma (MCL) and chronic lymphocytic leukemia (CLL): molecular analysis reveals mechanisms of target interactions. Blood. 2014;124(21):509-9.

72. Gerecitano J. SINE (selective inhibitor of nuclear export) - translational science in a new class of anti-cancer agents. J Hematol Oncol. 2014;7(1):67.

73. Gravina G, Senapedis W, McCauley D, Baloglu E, Shacham S, Festuccia C. Nucleo-cytoplasmic transport as a therapeutic target of cancer. J Hematol Oncol. 2014;7(1):85.

74. Gravina G, Tortoreto M, Mancini A, Addis A, Di Cesare E, Lenzi A, et al. XPO1/CRM1-selective inhibitors of nuclear export (SINE) reduce tumor spreading and improve overall survival in preclinical models of prostate cancer (PCa). J Hematol Oncol. 2014;7(1):46.

75. Parikh K, Cang S, Sekhri A, Liu D. Selective inhibitors of nuclear export (SINE)- a novel class of anti-cancer agents. J Hematol Oncol. 2014;7(1):78.

76. Das A, Wei G, Parikh K, Liu D. Selective inhibitors of nuclear export (SINE) in hematological malignancies. Exp Hematol Oncol. 2015;4:7.

77. Tabe $Y$, Harada M, Miyamae $Y$, Kazuno S, Fujimura T, Ueno T, et al. Selective inhibitor of nuclear export selinexor (KPT-330) and BCL2 inhibitor ABT-199 enhance the anti-lymphoma effect of BTK inhibitor ibrutinib in mantle cell lymphoma. Blood. 2014;124(21):2254-4. 
78. Lu S, Wang J. Homoharringtonine and omacetaxine for myeloid hematological malignancies. J Hematol Oncol. 2014;7(1):2.

79. Kozopas KM, Yang T, Buchan HL, Zhou P, Craig RW. MCL1, a gene expressed in programmed myeloid cell differentiation, has sequence similarity to BCL2. Proc Natl Acad Sci U S A. 1993;90(8):3516-20.

80. Klanova M, Andera L, Soukup J, Jan B, Svadlenka J, Benesova S, et al. MCL1 targeting agent homoharringtonine exerts strong cytotoxicity towards diffuse large B-cell lymphoma (DLBCL) cells and synergizes with BCL2 targeting agent ABT199 in eliminating BCL2-positive DLBCL cells. Blood. 2014; 124(21):3645-5.

81. Davids MS, Pagel JM, Kahl BS, Wierda WG, Miller TP, Gerecitano JF, et al. BCl-2 inhibitor ABT-199 (GDC-0199) monotherapy shows anti-tumor activity including complete remissions in high-risk relapsed/refractory $(R / R)$ chronic lymphocytic leukemia (CLL) and small lymphocytic lymphoma (SLL). Blood. 2013;122(21):872-2.

82. Ghia P, Hallek M. Management of chronic lymphocytic leukemia. Haematologica. 2014;99(6):965-72.

83. Seymour JF, Davids MS, Pagel JM, Kahl BS, Wierda WG, Puvvada S, et al. ABT-199 (GDC-0199) in relapsed/refractory (R/R) chronic lymphocytic leukemia (CLL) and small lymphocytic lymphoma (SLL): high completeresponse rate and durable disease control. ASCO Meeting Abstr. 2014; 32(15_suppl):7015.

84. Davids MS, Seymour JF, Gerecitano JF, Kahl BS, Pagel JM, Wierda WG, et al. Phase I study of ABT-199 (GDC-0199) in patients with relapsed/refractory (R/ R) non-Hodgkin lymphoma (NHL): responses observed in diffuse large B-cell (DLBCL) and follicular lymphoma (FL) at higher cohort doses. ASCO Meeting Abstr. 2014;32(15_suppl):8522.

85. Konopleva M, Pollyea DA, Potluri J, Chyla BJ, Busman T, McKeegan E, et al. A phase 2 study of ABT-199 (GDC-0199) in patients with acute myelogenous leukemia (AML). Blood. 2014;124(21):118-8.

86. Ma S, Seymour JF, Lanasa MC, Kipps TJ, Barrientos JC, Davids MS, et al, ABT-199 (GDC-0199) combined with rituximab (R) in patients (pts) with relapsed/refractory (R/R) chronic lymphocytic leukemia (CLL): Interim results of a phase 1b study. ASCO Meeting Abstr. 2014;32(15_suppl):7013.

87. Roberts AW, Ma S, Brander DM, Kipps TJ, Barrientos JC, Davids MS, et al. Determination of recommended phase 2 dose of ABT-199 (GDC-0199) combined with rituximab $(R)$ in patients with relapsed / refractory (R/R) chronic lymphocytic leukemia (CLL). Blood. 2014;124(21):325-5.

88. Mobasher M, Huang J, Elstrom RL, Elhamy M, Bernaards C, Hallek MJ, et al. Multicenter, phase III, open-label, randomized study in relapsed/refractory CLL to evaluate the benefit of GDC-0199 (ABT-199) plus rituximab compared with bendamustine plus rituximab. ASCO Meeting Abstr. 2014; 32(15_suppl):TPS7120.

89. de Vos S, Flowers CR, Wang D, Swinnen LJ, Fowler N, Reid E, et al. The BCL-2 inhibitor ABT-199 (GDC-0199) in combination with bendamustine and rituximab in patients with relapsed or refractory non-Hodgkin's lymphoma. Blood. 2014;124(21):1722.

90. Salles GA, Boyd TE, Morschhauser F, Wendtner C-M, Lymp J, Hilger J, et al. Preliminary results of a phase 1b study (GO28440) combining GDC-0199 (ABT-199) with bendamustine/rituximab in patients with relapsed/refractory or previously untreated chronic lymphocytic leukemia. Blood. 2014;124(21):3337.

91. Flinn I, Brunvand M, Dyer MJ, Hillman P, Jones J, Lymp J, et al. Preliminary results of a phase 1b study (GP28331) combining GDC-0199 (ABT-199) and obinutuzumab in patients with relapsed/refractory or previously untreated chronic lymphocytic leukemia. Blood. 2014;124(21):4687.

92. Wierda WG, Seymour JF, Roberts AW, Puvvada S, Davids MS, Wong S, et al. A phase 2 open-label study of the efficacy of ABT-199 (GDC-0199) in patients with relapsed or refractory $(R / R)$ chronic lymphocytic leukemia (CLL) harboring 17p deletion. ASCO Meeting Abstr. 2014;32(15_suppl):TPS7121.

93. Fresquet V, Rieger M, Carolis C, Garcia-Barchino MJ, Martinez-Climent JA. Acquired mutations in $\mathrm{BCL} 2$ family proteins conferring resistance to the BH3 mimetic ABT-199 in lymphoma. Blood. 2014;123(26):4111-9.

94. Choudhary GS, Al-Harbi S, Mazumder S, Hill BT, Smith MR, Bodo J, et al. MCL-1 and BCL-xL-dependent resistance to the BCL-2 inhibitor ABT-199 can be overcome by preventing PI3K/AKT/mTOR activation in lymphoid malignancies. Cell Death Dis. 2015;6:e1593.

95. Thijssen R, Slinger E, Weller K, Geest CR, Beaumont T, van Oers MH, et al. Resistance to ABT-199 induced by microenvironmental signals in chronic lymphocytic leukemia can be counteracted by CD20 antibodies or kinase inhibitors. Haematologica. 2015;100(8):e302-6.

\section{Submit your next manuscript to BioMed Central and take full advantage of:}

- Convenient online submission

- Thorough peer review

- No space constraints or color figure charges

- Immediate publication on acceptance

- Inclusion in PubMed, CAS, Scopus and Google Scholar

- Research which is freely available for redistribution

Submit your manuscript at www.biomedcentral.com/submit 